\title{
Study on the Impact of Perceived Network Externalities on Consumers' New Product Purchase Intention
}

\author{
Yong Zhang1, Gang Wan', Liuting Huang², Qiong Yao1 \\ ${ }^{1}$ Management School, Jinan University, Guangzhou, China \\ ${ }^{2}$ Human Resources and Social Security Bureau, Zhongshan, China \\ Email: wangang155@163.com
}

Received 26 December 2014; accepted 8 February 2015; published 13 February 2015

Copyright (C) 2015 by authors and Scientific Research Publishing Inc.

This work is licensed under the Creative Commons Attribution International License (CC BY). http://creativecommons.org/licenses/by/4.0/

(c) (i) Open Access

\section{Abstract}

In the network economy era, the impact of network externalities on consumers' new product purchase intention is increasingly significant. However, there is little empirical researches to explore the relationship between these two constructs. This research utilizes the Technology Acceptance Model (TAM) and combines it with perceived risk theory analyzing the relationship between perceived network externalities and new product purchase intention. The results of our empirical study show direct and indirect relationship. The perceived network externalities can influence consumers' new product purchase intention directly. In addition, they have an indirect impact by influencing the perceived usefulness, perceived ease of use, and perceived risk.

\section{Keywords}

Perceived Network Externalities, Perceived Risk, Purchase Intention, The Technology Acceptance Model (TAM)

\section{Introduction}

Along with the rapid development of social economy and technology, product life cycles are getting shorter, and the importance of research and development of new products are becoming increasingly significant in enterprise's business activities. However, the R \& D and promotion of new products, especially high-tech new products have higher risk and investment, which results in higher complexity, and combined with uncertainty and risk brought by the network externalities, it exerts a great influence on consumers' purchase intention [1]. In 
general, consumers are more willing to use or purchase products with larger network externalities, and generate greater trust and loyalty [2]. Therefore, how to enhance the purchase intention of new products with network externalities has become an important issue, not only for enterprises in their high-tech product competition strategy, but also for academia in developing a better theory system in this field.

At present, the studies about consumers' purchase intention mainly focuses on the measure and the influencing factor of purchase intention and the interaction relation between purchase intention and purchase behavior [3], etc., however, the study focused on the purchase intention of the new product with network externalities is poor. Meanwhile, the studies about network externalities are mainly concentrated on the classification and the market structure evolution of network externalities, modeling examing and discussing from social and business perspective, but the studies from consumers' perspective are still relatively scarce. To fulfill the absence, based on the technology acceptance model, this research points out that consumers' new product purchase intention is influenced by perceived usefulness and perceived ease of use, but also by perceived risk and perceived network externalities. It will not only increase the explanatory power of the TAM, but also build a theoretical model exploring the influencing factors when consumers buy the new products, and has an important significance for enterprises competition in high-tech products market.

\section{Literature Review}

\subsection{Technology Acceptance Model (TAM)}

Technology acceptance model is mainly used to explain and predict the users how to accept information systems or information technology, which consists of behavior intention, actual behavior, using attitude, perceived usefulness and perceived ease of use [4]. Among them, behavior intention is a kind of cognitive activity, reflecting the individual's willingness to adopt a particular behavior. The more someone's behavioral intention, the greater the possibility he will take action. Behavior attitude refers to the individual's negative or positive feeling about a specific behavior, affected by the individual's evaluation or ideas about a specific behavior. Perceived usefulness reflects the extent that the individual feels to use a particular system to improve his work efficiency or performance. And perceived ease of use reflects how easily the individual feels to use a particular system.

In TAM, actual behavior is determined directly by behavior intention, behavior intention is determined by both using attitude and perceived usefulness, using attitude is determined by both perceived ease of use and perceived usefulness, and perceived ease of use will strengthen perceived usefulness in some particular situations. Therefore, the external variables TAM insists will affect using attitude through impacting perceived usefulness and perceived ease of use, and ultimately affect the individual's actual behaviors.

Because of its good concision and handle-ability and strong pertinence, TAM has been widely applied to the studies about online shopping, mobile commerce and other fields. But it also has the following two aspects of flaw. First, it has not reflected the environmental factor of products using, as Dishaw and Strong (1999) [5] pointed out that the defect of TAM is lack of the tasks-focused. Second, it has not proposed the external barriers preventing the consumers from using products. Meanwhile, Hu et al. (1999) [3] also pointed out that, in applying TAM as the theoretical basis of research, other factors should be properly added to enhance the explanatory ability of the mode. Therefore, in order to predict the acceptance of technology products preferably, this study added perceived risk and perceived network externalities to enhance the explanatory power of TAM.

\subsection{Perceived Risk}

The concept of perceived risk was originally established in 1960 by Bauer [6], he pointed that consumers' purchase behaviors were likely to lead to hard-to-predict and even unpleasant outcomes. Therefore, consumers' purchase decision contains the uncertainty of the outcome, which was the initial concept of perceived risk. Then Cunningham (1967) [7] summarized the two factors of perceived risk on Bauer's basis, including the uncertainty and the severity of consequence. However, this view held simply that perceived risk is equal to the product of "uncertainty" and "severity", so cannot explain the over risk sufficiently. Therefore, from the perspective of psychological driving, Stone and Gronhaug (1993) [8] defined perceived risk as a forecast made by consumers about the loss, and divided it into economic risk, functional risk, physical risk, psychological risk, social risk and time risk. This definition can explain perceived risk better, and has been accepted by many scholars. For this reason, this research will use it to definite perceived risk. 


\subsection{Perceived Network Externalities}

Network externalities refers to the utility consumers gain from a product, which will change along with the change of the number of consumers [9]. Many studies showed that network externalities could lead to the "locked" phenomenon of consumer market directly, that's to say, the network externalities consumers perceiving will affect their decisions to give up the old products and choose the new ones, and not replace the manufacturers easily due to the specialized assets accumulated by the previous products, such as, individual utility, social utility, precipitation, etc. The source of network externalities can be roughly divided into two categories: direct network externalities and indirect network externalities. Direct network externalities refers to the improvement of consumers' utility along with the increase of same products customers, which mainly reflects the interdependence between consumers in the same market [10]. Indirect network externalities mainly generates in the mutually supportive relation between basic products and complementary products, that's to say, the more prominent of the advantages of quantity and quality of a basic product and its complementary products are, the more the utility consumers will derive from the product [9]. On this basis, from the perspective of consumer perception, this study will replace actual product complementarity with perceived product complementarity, and replace actual customer installed base with perceived customer install base, so as to explore how will perceived network externalities impact on new product purchase intention.

\section{Research Hypothesis}

\subsection{Perceived Usefulness, Perceived Ease of Use and New Product Purchase Intention}

In TAM, perceived usefulness and perceived ease of use can affect using attitude directly, and thus indirectly affect behavior intention. Moreover, perceived usefulness can directly affect behavior intention, and behavior intention can directly affect consumers' actual behavior [4]. TAM has been widely applied to the studies about the adoption of information system, and can predict and analyze consumers' actual use or purchase behavior of technology products well [10]. In the research field of new products purchase intention, unlike information systems, the new products are no longer available directly to the user, it can only be used after they bought them, but consumers' actual purchasing behavior also be affected directly by purchase intention. Therefore, in this study, new products purchase intention denotes a kind of cognitive activity, reflecting consumers intention to adopt new products, and will be affected by perceived usefulness and perceived ease of use [10]. On one hand, the more useful consumers believed the new products are, the more likely they will purchase them. On the other hand, the more easily to be used consumers perceived the new products are, the greater likelihood they will buy them, that's to say, perceived ease of use will strengthen their perceived usefulness to some extent. Based on the above analysis, we introduced the following hypothesis:

H1: consumers' perceived usefulness has significant positive impact on new product purchase intention.

H2: consumers' perceived ease of use has significant positive impact on new product purchase intention.

H3: consumers' perceived ease of use has significant positive impact on perceived usefulness.

\subsection{Perceived Risk, Perceived Usefulness, and New Products Purchase Intention}

When Consumers purchase new products, their behavior will produce certain perceived risks because of the uncertainty of the results [7]. A large number of studies have shown that these risks have a close relation with perceived usefulness and new product purchase intention. Featherman et al. (2003) [11] confirmed that the perceived risk would generally reduce perceived usefulness and product adoption. Lu et al. (2005) [12] studied taiwanese Internet consumers' behavior intention, and found that perceived risk has a negative correlation with perceived usefulness, and can significantly affect consumers' continuance intention. Vijayasarathy et al.'s (2000) [13] study pointed that there was a negative correlation between perceived risk and consumers' new products purchase intention. Therefore we put forward the following hypothesis:

H4: consumers' perceived risk has significant positive impact on new product purchase intention.

H5: consumers’ perceived risk has significant positive impact on perceived usefulness.

\subsection{Perceived Network Externalities, Perceived Risk, Perceived Usefulness, Perceived Ease of Use and New Products Purchase Intention}

This study, from the perspective of consumer perception, divided the perceived network externalities into two 
categories: perceived customer install base and perceived product complementarity. Some studies showed that, when consumers buy the new products, their purchase intention will be impacted by the perceived customer install base, so as to reduce the uncertainty of their decisions and improve their utility. Many researches in Industrial Economics field denoted that, if there are network externalities in the industry, the number of customer install base will affect purchase decisions [14]. Bental and Spiegel (1995) [15], and Padmanabhan et al.’s (1997) [16] studies confirmed that perceived customer install base could directly or indirectly improve consumers' new products purchase intention by increasing the utility of the products, or promoting information sharing and support between consumers, or reducing the uncertainty of the upgrade of high-tech new products.

Moreover, when perceiving a large number of the consumers using the new products, it will encourage new consumers to learn the features of new product, and promote the new and old consumers to communicate their usages and experiences. It makes the new consumers can quickly learn how to use new products and realize its value, and then hold positive attitudes toward buying them. Wang et al. (2005) [10] studied consumers' adoption about network instant messaging service, he pointed that perceived customer install base has significant direct impact on perceived usefulness and perceived ease of use, it can also affect consumers' adoption intention. In addition, the larger the number of customer install base is, the more likely it will reduce consumers' perceived risks about new products because potential customers will estimate the value of new products according to other consumers' buy, experiences, and praises. For example, by consulting the current consumers' advice, potential customers can reduce their time risk to learn using new products; when potential customers realize that there are so many people have purchase new products, they will believe quality is indeed good, thus reduce the functional risk and psychological risk, etc. Therefore we put forward the following hypothesis:

H6: consumers’ perceived customer install base has significant positive impact on new product purchase intention.

H7: consumers' perceived customer install base has significant positive impact on perceived usefulness.

H8: consumers' perceived customer install base has significant positive impact on perceived ease of use.

H9: consumers’ perceived customer install base has significant negative impact on perceived risk.

Perceived product complementarity is mainly reflected in the quality and quantity of complementary products perceived by consumers. Many studies showed that the number of new product's complementary products, and the number of consumers that have bought complementary products also has positive impact on consumers' perceived usefulness and perceived ease of use. For example, Chaohua Deng et al. (2007) [17] studied the consumers' mobile service use behavior in mobile environment, and confirmed that the number of consumers' perceived complementary products would impact significantly consumers' new products perceived usefulness and perceived ease of use. Hung et al. (2003) [18], by empirical study, also found that the number of complementary products had positive impact on mobile business users' perceived usefulness and perceived ease of use. More formally, we hypothesized that:

H10: consumers' perceived product complementarity has significant positive impact on perceived usefulness.

H11: consumers’ perceived product complementarity has significant positive impact on perceived ease of use.

\section{Study Design}

This paper adopted the method of random sampling, organizing questionnaire survey to collect data. The participants were mainly from full-time students of a university in s southern China, and the experimental stimulus is tablet PC. Because the students' well understanding network externalities and a keen sight of high-tech new products, and tablet PC is a representative sample of high-tech products, the authenticity of the study's result is persuasive. The measurement scale of this study was mainly based on the existing mature scales domestic and overseas, we modified according to the actual background of this research.

Before the formal finalized questionnaire and investigation, we carried out a pre-survey on some consumers to assess the appropriateness of questionnaire design and diction, and then revised repeatedly our questionnaire according to the consumers' advices. The measures used are the 7-point Likert-type scales with the anchors $1=$ strongly disagree to 7 = strongly agree. The questionnaire was comprised of three parts: first, we simply presented research background to all participants, and then asked them whether they had understood the background above; second, we requested the participants to score according to their own actual feelings; finally, we collected personal basic information such as age, sex and education, etc. At last, we distributed a total of 349 questionnaires in the formal investigation, recycled 336 questionnaires, excluded 41 questionnaires that could 
not fulfill to the requirements. Therefore the final number of effective questionnaire is 295 , and the effective rate is $87.79 \%$.

\section{Results}

\subsection{Reliability and Validity}

This research used SPSS18.0 and AMOS17.0 to process and analyze the data. To analyze the reliability and validity of the questionnaire, the result showed that all variables' Cronbach's alpha coefficient were higher than 0.79 , which indicated that internal consistency of each variable is better and our scale has good reliability. We used factor analysis method to measure the structural validity of the questionnaire. If KMO value is greater than 0.7 , Bartlett sphere test $(\mathrm{p}=0.000)$ reaches significance level, the scale is suitable for factor analysis. On this basis, we used principal component factor analysis and varimax rotation to carry out exploratory factor analysis for each variable, and the result showed that the factor loadings of all variable is between 0.7 to 0.9 , indicating that the questionnaire has good structure validity (see Table 1).

Table 1. Results of the reliability and validity analysis.

\begin{tabular}{|c|c|c|c|c|c|}
\hline Constructs & Code name & Factor loadings & Cronbach's $\alpha$ & KMO value & Bartlett sphere test \\
\hline \multirow{3}{*}{$\begin{array}{l}\text { Perceived customer } \\
\text { install base }\end{array}$} & PIB1 & 0.859 & \multirow{3}{*}{0.869} & \multirow{3}{*}{0.709} & \multirow{3}{*}{0.000} \\
\hline & PIB2 & 0.750 & & & \\
\hline & PIB3 & 0.785 & & & \\
\hline \multirow{3}{*}{$\begin{array}{c}\text { Perceived product } \\
\text { complementarity }\end{array}$} & PC4 & 0.707 & \multirow{3}{*}{0.802} & \multirow{3}{*}{0.701} & \multirow{3}{*}{0.000} \\
\hline & PC5 & 0.779 & & & \\
\hline & PC6 & 0.773 & & & \\
\hline \multirow{12}{*}{ Perceived risk } & PhR7 & 0.873 & \multirow{12}{*}{0.795} & \multirow{12}{*}{0.769} & \multirow{12}{*}{0.000} \\
\hline & PhR8 & 0.841 & & & \\
\hline & SR9 & 0.913 & & & \\
\hline & SR10 & 0.877 & & & \\
\hline & FR11 & 0.789 & & & \\
\hline & FR12 & 0.687 & & & \\
\hline & PR13 & 0.872 & & & \\
\hline & PR14 & 0.841 & & & \\
\hline & PsR15 & 0.880 & & & \\
\hline & PsR16 & 0.899 & & & \\
\hline & TR17 & 0.860 & & & \\
\hline & TR18 & 0.856 & & & \\
\hline \multirow{4}{*}{ Perceived usefulness } & PU19 & 0.751 & \multirow{4}{*}{0.849} & \multirow{4}{*}{0.773} & \multirow{4}{*}{0.000} \\
\hline & PU20 & 0.796 & & & \\
\hline & PU21 & 0.823 & & & \\
\hline & PU22 & 0.898 & & & \\
\hline \multirow{4}{*}{ Perceived ease of use } & PE23 & 0.806 & \multirow{4}{*}{0.838} & \multirow{4}{*}{0.756} & \multirow{4}{*}{0.000} \\
\hline & PE24 & 0.809 & & & \\
\hline & PE25 & 0.774 & & & \\
\hline & PE26 & 0.726 & & & \\
\hline \multirow{3}{*}{$\begin{array}{c}\text { New products } \\
\text { purchase intention }\end{array}$} & PI27 & 0.864 & \multirow{3}{*}{0.797} & \multirow{3}{*}{0.773} & \multirow{3}{*}{0.000} \\
\hline & PI28 & 0.850 & & & \\
\hline & PI29 & 0.795 & & & \\
\hline
\end{tabular}




\subsection{The Results of SEM}

We used AMOS17.0, a kind of structural equation statistical software, to explore the interaction relationship between the variables. The results showed that all the fitting indexes have achieved the criteria $(\mathrm{c} 2 / \mathrm{df}=3.86<5$; $\mathrm{GFI}=0.876>0.7$; RMSEA $=0.079<0.08 ; \mathrm{CFI}=0.906>0.9$; TLI $=0.857>0.7$ ). It indicated that the model had very strong powers of persuasion for hypothesis argument. On the basis above, we tested the hypotheses of research model according to the standardized coefficient, CR value and significant level. The test of the model data is shown in Table 2. From the empirical analysis results, in addition to the standardized path coefficient of perceive products complementarity on perceived ease of use, the other standardized path coefficient between the variables we want to discuss have reached the significant levels. It indicated that, besides H11, the remaining hypotheses were supported.

\section{Results}

Based on the background of high-tech products network externalities and on the framework of TAM, this research integrated perceived risk, perceived customer install base, perceived product complementarity, etc. to construct a new analyze system. By it, we analyzed the influence mechanism of perceived network externalities on new products purchase intention through empirical study.

The theoretical contributions are the followings. On the one hand, the structures of previous studies on TAM theory was too simple; they studied products purchase intention only from the perspective of the consumers' benefits to, ignoring the impact of perceived risk on consumers' new product purchase intention. Combined TAM theory with perceived risk theory, we found that, besides perceived usefulness and perceived ease of use, consumers would consider products possible risks before making purchase decisions, at the same time, perceived network externalities had a primitive effect on purchase intention., On the other hand, we divided perceived network externalities into perceived customer install base and perceived product complementarity, not enriching previous research on network externalities which just confined to customer installed base. It lay a foundation for properly understanding the impact perceived network externalities on new product purchase intention.

Meanwhile, this research has guiding significance to enterprise practices to some extent. First of all, attention needs to be paid to the management of consumer expectation and the expanding of customer installed base. In the network externalities market, consumer expectation will affect their choices for new products. Therefore, enterprises should pay attention to influence consumer expectations as much as possible when promoting new products, thereby expanding enterprises' customer installed base and attracting more buyers. Secondly, it is important to strengthen the cooperation with enterprises providing complementary products. Because of the exis-

Table 2. Results of path coefficient estimation.

\begin{tabular}{|c|c|c|c|c|}
\hline Path & $\begin{array}{c}\text { Standardized } \\
\text { estimates parameter }\end{array}$ & $\mathbf{P}$ & Hypothesis & Test result \\
\hline Perceived usefulness $\rightarrow$ New products purchase intention & 0.271 & $* * *$ & H1 & Support \\
\hline Perceived ease of use $\rightarrow$ New products purchase intention & 0.314 & $* * *$ & $\mathrm{H} 2$ & Support \\
\hline Perceived ease of use $\rightarrow$ Perceived usefulness & 0.304 & 0.001 & H3 & Support \\
\hline Perceived risk $\rightarrow$ New products purchase intention & -0.509 & $* * *$ & $\mathrm{H} 4$ & Support \\
\hline Perceived risk $\rightarrow$ Perceived usefulness & 0.271 & 0.036 & H5 & Support \\
\hline Perceived customer install base $\rightarrow$ New products purchase intention & 0.178 & 0.027 & H6 & Support \\
\hline Perceived customer install base $\rightarrow$ Perceived usefulness & 0.125 & 0.849 & $\mathrm{H} 7$ & Support \\
\hline Perceived customer install base $\rightarrow$ Perceived ease of use & 0.335 & $* * *$ & H8 & Support \\
\hline Perceived customer install base $\rightarrow$ Perceived risk & -0.140 & 0.005 & H9 & Support \\
\hline Perceived product complementarity $\rightarrow$ Perceived usefulness & 0.364 & 0.004 & H10 & Support \\
\hline Perceived product complementarity $\rightarrow$ Perceived ease of use & 0.529 & 0.038 & H11 & Nonsupport \\
\hline
\end{tabular}

Note: ${ }^{* * *}$ the level of significance is less than $0.001(\mathrm{P}<0.001)$. 
tence of the indirect network externalities effect and the incompatibility of product technology, enterprise's survival and development, to a certain extent, depend on their complementary products. In order to win the fierce competition in the high-tech products market, enterprises should develop more solid and extensive cooperation with enterprises providing complementary products, so as to enhance consumers' identification of new products. And last, it is crucial to improve the quality and reputation of corporate brand. On the one hand, excellent brand quality and reputation will help enterprises get the positive feedback of products' network externalities, on the other hand, corporate brand quality and reputation is valuable intangible assets, which can enhance customer loyalty and improve products' differentiation, thereby reducing consumers' perceived risk in adopting the new products.

Although we have got important conclusions for enterprises management theory and practice, there are still some shortcomings. This research, from the perspective of consumers, explored the impact network externalities on new product purchase intention, but network externality is a broad concept; future studies can do more indepth researches from switching costs, locking effect, etc. Moreover, the samples were mainly from full-time students of a university in southern China, and the experimental stimulus were relatively simple, so the survey data may have some limitations. Future research should attempt to survey in a larger scope and wider industry domains, testing to further the conclusion of this paper.

\section{Acknowledgements}

This study was supported by the National Natural Science Foundation of China (71002085), and the Humanity and Social Science Youth foundation of Ministry of Education of China (09YJC630101).

\section{References}

[1] Lazarus, R.S. (1996) Cognition and Motivation in Emotion. American Psychologist, 46, 352. http://dx.doi.org/10.1037/0003-066X.46.4.352

[2] Economides, N. (1999) The Economics of Networks. International Journal of Industrial Organization, 14, 673-699. http://dx.doi.org/10.1016/0167-7187(96)01015-6

[3] Hu, P.J., Chau, P.Y.K., Sheng, O.R.L., et al. (1999) Examining The Technology Acceptance Model Using Physician Acceptance of Telemedicine Technology. Journal of Management Information Systems, 16, 91-112.

[4] Davis, F.D. (1986) A Technology Acceptance Model for Empirically Testing New End-User Information Systems: Theory and Results. Sloan School of Management, Massachusetts Institute of Technology.

[5] Dishaw, M.T. and Strong, D.M. (1999) Extending the Technology Acceptance Model with Task-technology Fit Constructs. Information \& Management, 36.

[6] Bauer, R.A. (1960) Consumer Behavior as Risk Taking. In: Hancock, R.S., Ed., Dynamic Marketing for a Changing World, Proceedings of the 43rd. Conference of the American Marketing Association, 389-398.

[7] Cunningham, S.M. (1967) The Major Dimensions of Perceived Risk. Risk Taking and Information Handling in Consumer Behavior, 82-108.

[8] Stone, R.N. and Gronhaug, K. (1993) Pereeived Risk: Further Considerations for the Marketing Discipline. European Journal of Marketing, 27, 39-50. http://dx.doi.org/10.1108/03090569310026637

[9] Katz, M.L. and Shapiro, C. (1985) Network Externalities, Competition, and Compatibility. The American Economic Review, 75, 424-440.

[10] Wang, C.C., Hsu, Y.H. and Fang, W.C. (2004) Acceptance of Technology with Network Externalities: An Empirical Study of Internet Instant Messaging Services. Journal of Information Technology Theory and Application, 6, 15-28.

[11] Featherman, M.S. and Pavlou, P.A. (2003) Predicting E-Services Adoption: A Perceived Risk Fakes Perspective. International Journal of Human-Computer Studies, 59, 451-474. http://dx.doi.org/10.1016/S1071-5819(03)00111-3

[12] Lu, H.P., Hsu, C.L. and Hsu, H.Y. (2005) An Empirical Study of the Effect of Perceived Risk upon Intention to Use Online Applications. Information Management \& Computer Security, 13, 106-120. http://dx.doi.org/10.1108/09685220510589299

[13] Vijayasarathy, L.R. and Jones, J.M. (2000) Print and Internet Catalog Shopping: Assessing Attitudes and Intentions. Internet Research, 10, 191-202. http://dx.doi.org/10.1108/10662240010331948

[14] Schilling, M.A. (2002) Technology Success and Failure in Winner-Take-All Markets: The Impact of Learning Orientation, Timing and Network Externalities. Academy of Management Journal, 45, 387-398. http://dx.doi.org/10.2307/3069353 
[15] Bental, B. and Spiegel, M. (1995) Network Competition, Product Quality and Market Coverage in the Presence of Network Externalities. The Journal of Industrial Economics, 43, 197-208. http://dx.doi.org/10.2307/2950481

[16] Padmanabhan, V., Rajiv, S. and Srinivasan, K. (1997) New Products, Upgrades, and New Releases: A Rationale for Sequential Product Introduction. Journal of Marketing Research, 34, 456-72. http://dx.doi.org/10.2307/3151964

[17] Deng, C., Lu, Y. and Zhang, J. (2007) Study on Mobile Services Using Behavior on the Base of TAM and Network Externalities. Journal of management, 4, 216-221.

[18] Hung, S.Y., Ku, C.Y. and Chang, C.M. (2003) Critical Factors of WAP Services Adoption: An Empirical Study. Electronic Commerce Research and Applications, 2, 42-60. http://dx.doi.org/10.1016/S1567-4223(03)00008-5 
Scientific Research Publishing (SCIRP) is one of the largest Open Access journal publishers. It is currently publishing more than 200 open access, online, peer-reviewed journals covering a wide range of academic disciplines. SCIRP serves the worldwide academic communities and contributes to the progress and application of science with its publication.

Other selected journals from SCIRP are listed as below. Submit your manuscript to us via either submit@scirp.org or Online Submission Portal.
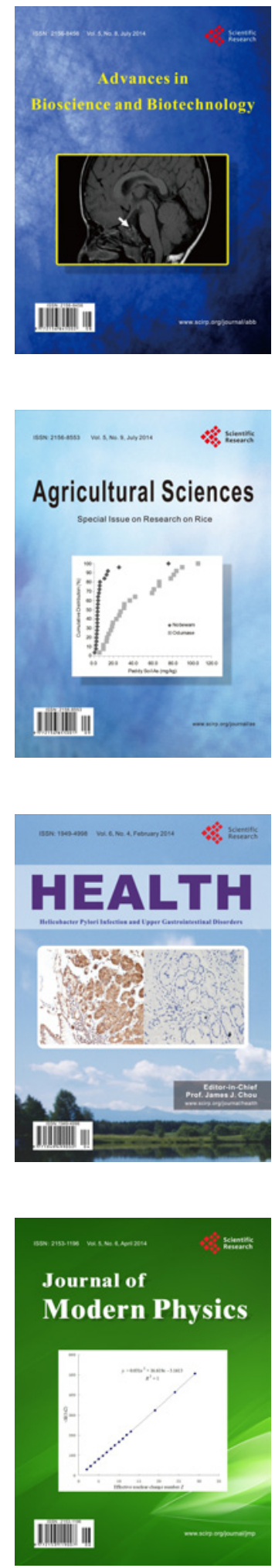
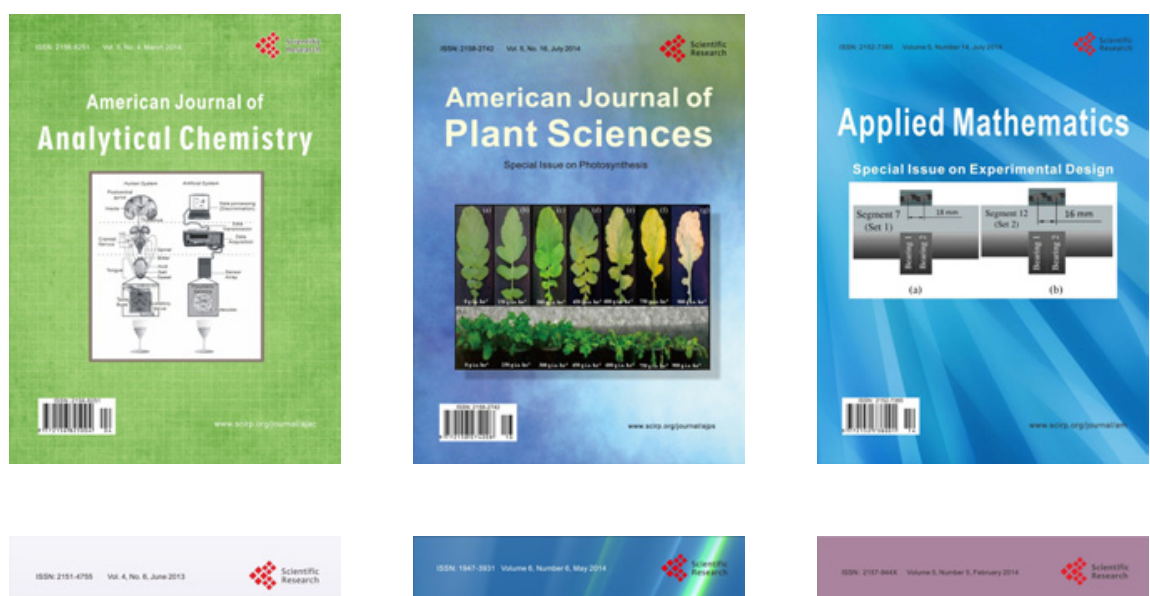

Creative Education
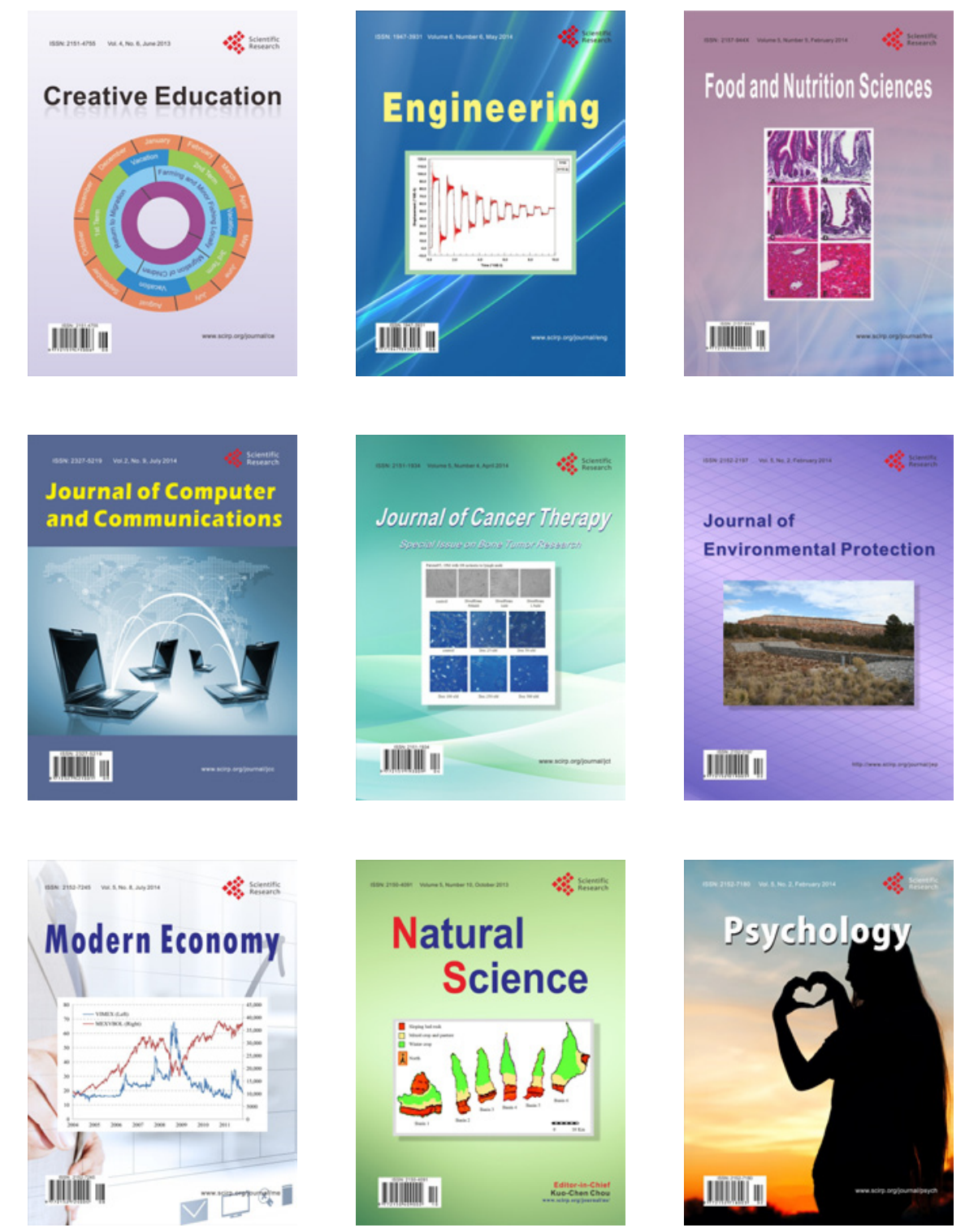